\title{
Opening the black box of CSR decision making: A policy-capturing study of charitable donation decisions in $\mathrm{China}^{1}$
}

\author{
Shuo Wang \\ Huarong Asset Management CO., LTD \\ Email:shuo.wang2008@gmail.com \\ Yuhui Gao \\ Dublin City University \\ Email:yuhui.gao@dcu.ie \\ Gerard P. Hodgkinson* \\ University of Warwick \\ Email: Gerard.Hodgkinson@wbs.ac.uk \\ Tel: +44(0)7717695152 \\ Denise M. Rousseau \\ Carnegie Mellon University \\ Email:rousseau@andrew.cmu.edu \\ Patrick C. Flood \\ Dublin City University \\ Email: patrick.flood@dcu.ie
}

Economics and Management School, Wuhan University, Hubei Province, China and China

* To whom correspondence should be addressed.

NOTES

${ }^{1}$ We are grateful to Professors Bin Xu, Xinbo Sun, Mengxia Zhang, Keqin Song, Associate

Professor Hui Hu, Ms.Xiaoxia Wang and Ms. Lei Zhang for their assistance with the data collection. 


\title{
Opening the black box of CSR decision making:
}

\section{A policy-capturing study of charitable donation decisions in China}

\begin{abstract}
This policy capturing study, conducted in China, investigated the cognitive basis of managerial decisions to make a corporate charitable donation, a global issue in the context of Corporate Social Responsibility (CSR) research and practice. Participants (N=376) responded to a series of scenarios manipulating pressure from the five stakeholders (government, customers, competitors, employees, and shareholders) most commonly addressed by CSR research. The independent variables examined included organizational factors (industry, ownership, previous company donation, firm size, firm age and perceived CEO attitudes toward charity) and the participants' personal values. Results indicate a large positive effect of shareholder and governmental pressure on the decision with lesser positive effects from customers and competitors. Surprisingly, employee pressure had a negative effect on the decision to make a charitable donation. Further, personal values and CEO attitudes toward charity were significantly related to the decisions participants made. In line with our theorizing, the findings indicate that a combination of personal, organizational, and institutional factors are salient in the minds of decision makers.
\end{abstract}

Key Words: corporate social responsibility, policy-capturing study, stakeholder salience theory, upper echelons theory and Chinese management, strategic decision making 


\section{Introduction}

Corporate social responsibility (CSR) is a strategic imperative for many stakeholders of modern firms. CSR refers to efforts by organizations to have a positive impact on the society at large, thus serving the interests of a wider public. It embraces a broad range of corporate activities to meet perceived societal or stakeholder obligations (Luo and Bhattacharya, 2006). Many firms incorporate CSR activities into their corporate strategy to enhance both their reputation and competitive advantage (McWilliams et al., 2006). Well-formulated CSR policies and practices play a key role in supporting firms' environmental management (Aguilera et al., 2007) and sustainable development (Steurer, et al., 2005; McWilliams et al., 2006), corporate reputation (Turban and Greening, 1997), and financial performance (McWilliams and Siegel, 2000). However, the basic cognitive processes of decision makers who enact CSR policy decisions have not been investigated. Study of CSR decision processes is a vital prerequisite for developing insights into how individuals as well as firms differ in their CSR-related responses.

The present study makes several contributions. First, it examines the mental representations of individuals making CSR-related decisions. Previous CSR research has focused primarily on the characteristics of firms engaging in CSR activities and associated outcomes (e.g., Agle et al., 1999; Brammer and Millington, 2004), treating the decision making process behind CSR activities as a black box. By investigating the underlying mechanisms that motivate individual decision makers to engage in CSR-related activities, the present study addresses this shortfall. In doing so, it indicates the extent to which, and in what ways, the revealed CSR-related decisions correspond with the decision outcomes individuals 
favor.

Second, this study introduces the technique of policy-capturing (PC) (Zhou and Martocchio, 2001) to the study of CSR. This technique requires participants to evaluate scenarios based on factorial combinations of criteria that theory specifies as the likely bases for their decisions. PC provides access to participants" "theories in use" (what people actually do) as distinct from their "espoused theories in action" (what people say they do) (Tyler and Steensma, 1998). Scholars are clearly divided as to the underlying motivations of decision makers for making corporate charitable donations (cf. Brammer and Millington, 2004; Sánchez, 2000; Su and He, 2010) and studies of the sort reported in the present article can go a long way toward addressing this puzzle. By ascertaining which stakeholder claims take precedence in the minds of decision makers, we move closer toward inferring which of these underlying motivations drive actual outcomes, or more precisely in what combination the various motivations exert their effects. The fundamental question as to whether their motivations are essentially philanthropic/altruistic or self-serving demands approaches to data collection that address this issue indirectly, so as not to simply elicit responses contaminated by social desirability bias. PC is an ideal technique for this purpose. Numerous studies have deployed PC successfully in investigating organizationally relevant decisions including job performance ratings (Spence and Keeping, 2010), executives' evaluations of technological alliance opportunities (Tyler and Steensma, 1998), international joint ventures (Reuer et al., 2011), and human resource management (HRM) decisions (Rotundo and Sackett, 2002; Rousseau and Anton, 1988; 1991). To the best of our knowledge, however, the method has not yet been employed in the domain of CSR. Through use of policy capturing the present study 
is able to investigate both within-person differences in the decisions of individuals as well as the between-person differences in values and organizational context that contribute to these decisions.

Third, our study focuses on an increasingly important and understudied aspect of CSR, that is, the decision to make charitable donations on behalf of the firm. Charitable donation is the contribution of valuable resources to support the public good (e.g., disaster relief or financial support to needy children). Charitable donation refers to money or other resources such as time and materials given to help others with whom one has no particular relationship and without expectation of direct reciprocity. Such corporate donations are on the rise globally, not only in Western countries, but also in other economies that do business with the West, such as China (Gao, 2010). It is in the distinct context of China that we seek to investigate this phenomenon, through an analysis of the beliefs and contextual factors motivating individuals to make such donations on behalf of their organizations.

\section{INSERT FIGURE 1 ABOUT HERE}

Recent years have seen substantial corporate charitable donation in China. Zhang et al. (2010) found that the mean and median respectively of corporate contributions in response to Sichuan earthquake (also known as the Great Wenchuan Earthquake) for the 703 Chinese firms studied were 3,086,688 and 1,001,000 RMB (note: 1 million RMB is roughly equivalent to $€ 123,000$ ). Although the Sichuan earthquake may be a special case, in a more general study of the effects of philanthropic activity on profitability in the Chinese context, $\mathrm{Su}$ and $\mathrm{He}$ 
(2010) found that the mean donation derived from the sample of 3,837 Chinese private enterprises surveyed (2006 data) was approximately 414,000 RMB (although the median was 50,000 RMB). Su and He (2010) suggest that larger firms tend to donate more. According to official statistics compiled by the Chinese government, as shown in Figure 1, charitable donation in general has risen markedly over the past decade, peaking dramatically in 2008, in the wake of the Sichuan earthquake. Since then donation has fluctuated up and down at much higher levels (circa 50-60 billion Yuan) relative to the years preceding that event.

Charitable donation is a discretionary activity that is not required or mandated (Waddock and Graves, 1997). Its ascendancy raises the question as to why, when faced with the opportunity to donate to worthy causes, some organizations donate generously, whereas others make only modest contributions and still others none at all. Only a few studies have addressed this important facet of CSR (e.g., Brammer and Millington, 2004). Previous literature has suggested three distinctive views on corporate philanthropy: altruistic, profit maximization, and political and institutional power views (e.g., Sánchez, 2000). The profit maximization view suggests that firms undertake philanthropic activities as long as direct economic benefit can be gained, for example tax benefits by US firms. Tax benefits are less likely to motivate philanthropic giving in China at present as only around 3\% of all the charity organizations in China are tax exempt (Su and He, 2010). Instead, as found by Su and He (2010), Chinese private sector organizations are more likely to donate to achieve better property rights and stronger political connections, supporting the political and institutional power view of corporate philanthropy. Based on the data of Chinese firms' response to the 2008 Sichuan earthquake, Zhang et al., (2009) found that corporate philanthropic disaster response decisions 
were influenced significantly by the firm's type of ownership; more specifically, the likelihood and extent of corporate contributions for state-owned firms were less than those for private firms. They further explained that China's partial privatization of state owned enterprises (SOEs) and the government's reluctance to relinquish a subset of its property rights with regard to its enterprises could have significantly negative consequences on firms' participation in corporate philanthropy. Zhang et al., (2009) further suggested that Chinese firms' response to corporate philanthropy is 'strategic and economics driven' (p.61). This view is consistent with Li and Zhang's (2010) study; it concluded that Chinese SOEs' response to CSR is both politically and economically motivated.

The time is ripe to investigate the factors behind CSR's global emergence. Countries such as China and India are seeking to build their reputation as global citizens (Chapple and Moon, 2005). China in particular has experienced an accelerated rate of economic growth along with a social revolution accompanied by well-documented social and political problems. Following China's entry into the World Trade Organization in 2001, Chinese companies have come under intense pressure to improve their CSR reputation in the wake of a host of scandals pertaining to labor relations, product defects, and air pollution (Gao, 2010). Chinese firms under high institutional pressure from external stakeholders such as the media and government engage in more CSR activities than do firms under lower institutional pressure (Gao, 2010). Moreover, Yin and Zhang (2012) suggest that the Chinese CSR understanding is influenced largely by the role of ethical leadership, governmental dependency, and the Confucian cultural traditions. A study of the CSR-related decision making of Chinese organizational decision makers thus seems particularly appropriate at this juncture. 


\section{Theoretical Background}

\section{Upper Echelons Theory}

The present study is guided by Hambrick and Mason's (1994) upper echelons theory of strategic decision making (SDM) under bounded rationality (see also Hambrick, 2007). This theory explicates how the background characteristics of senior executives in firms influence their decisions. In essence, it posits two related principles: (1) executives make decisions based on their interpretations of the organizational circumstances that they are involved in, and (2) their interpretations of those circumstances are necessarily partial, informed by the "administrative givens" they bring to bear on the situation at hand, in turn originating from their education, prior work experience, personal values, and a host of related individual differences that direct their attention selectively and shape their perceptions. Accordingly, the present study incorporates a range of individual factors that theory suggests might influence individuals' decisions to make corporate charitable donations, namely, their personal values and their perceptions of their CEOs' attitudes toward the charity in question.

Organizational factors are also known to impact on SDM (Elbanna and Child, 2007). In their review, Elbanna and Child (2007) found that organizational structure, power distribution, previous corporate strategies, firm size, and corporate control all impact on SDM.

Accordingly, the present study also incorporates a range of organizational factors that theory suggests are likely to influence individual managers' decisions to make or decline to make charitable donations, namely, industry, ownership, previous company donation (i.e. donation history), firm size, and firm age. 


\section{Stakeholder Salience and the Effects of Stakeholder Claims}

The stakeholder perspective on corporate strategy has had a large influence on CSR theory and research (e.g., Joyner and Payne, 2002; Buysse and Verbeke, 2003; Garriga and Melé, 2004; Nutt, 2004). Corporate strategy is adjusted regularly to reflect the expectations of salient stakeholders (e.g., Buysse and Verbeke, 2003; Driscoll and Starik, 2004). Not surprisingly numerous stakeholders have been found to play a role in CSR-related decisions including employees, owners or shareholders, suppliers, customers, community, and government (Mitchell et al., 1997). Executives generally recognize that employees, customers and shareholders are sensitive to the firm's public image and that CSR-related activities help shape that image. Activities that enhance corporate reputation can generate inimitable advantages by making it easier to attract customers and recruit employees (Turban and Greening, 1997) and by offering protection from "the potential for loss of value (from)... expenses associated with adverse legislation, regulatory penalties, or consumer retaliation" (Harrison et al., 2010, p. 59).

Stakeholders play an important role in the determination of corporate strategy. Yet not all stakeholders are equal in the context of corporate strategy or in the minds of strategic decision makers. The differential effects of stakeholders are predicated on the concept of stakeholder salience, that is, "the degree to which managers give priority to competing stakeholders' claims" (Agle et al., 1999, p. 508). Salience is shaped by three key attributes of stakeholder claims: legitimacy, power, and urgency. Legitimacy represents a claim based upon legal rights, contract, or moral interests derived from the actions of the organization (Suchman, 1995). Power refers to a relationship in which one actor or entity can, without legitimate claims, 
induce another to do something (Pfeffer, 1981). Urgency indicates the extent to which immediate action is called for by the stakeholder's claim (Mitchell et al., 1997). By combining these three facets, the concept of stakeholder salience has been used to explicate strategic management issues. Based on the actual and anticipated responses of stakeholders, executives and other organizational decision makers are prone to accept proposals for strategic action framed in terms of the most salient stakeholder claims, reducing concomitantly their attention to the merits of proposals (Nutt, 2004).

Many studies have demonstrated that SDM reflects stakeholders' concerns and pressures (Brammer and Millington, 2004; Brammer et al., 2009), consistent with the finding of Agle et al. (1999) that when CEOs ascribe high importance to stakeholders, their companies tend to achieve higher corporate social performance. Hence, we hypothesize:

H1: The greater the level of perceived pressure pertaining to a given stakeholder, the greater the influence of that stakeholder in explaining a given individual's decision to make charitable donations on the firm's behalf.

Responsiveness to stakeholder claims is a major driver of managerial decision making (McWilliams and Siegel, 2001; Mujtaba, 2010). To investigate the role of stakeholders in the making of corporate donation decisions, those stakeholders likely to be important must be identified. To do so we first examined the existing literature. Five stakeholders (i.e., shareholders, employees, government, customers, and competitors) are widely discussed in the context of CSR (Carroll, 1991; Marrewijk, 2003). We conducted interviews with Chinese senior managers to learn which stakeholders they believed to be most important. These interview results were consistent with the five stakeholders identified in the literature. 
The bases on which shareholders value CSR activities are numerous. First, shareholders can construe CSR activity as an ethical investment (Trevino, 1986). Reputational benefits from CSR can play a role in advertising to customers, reflecting the company's concern over the effect of corporate reputation on customer purchasing behavior (Brammer and Millington, 2004). Anticipating positive reactions on the part of employees to being employed by an ethical organization often guides decision makers in taking public actions like CSR-related activities (Trevino, 1986). Acknowledging the interests of governmental agencies and officials leads decision makers to make special effort to both comply with government policy and attempt to reduce governmental monitoring and improve their firms' corporate image (Brammer and Millington, 2004). Finally, imitation can play a role because decision makers are likely to feel a degree of normative pressure when their competitors engage in CSR actions (DiMaggio and Powell, 1983; Porter and Kramer, 2006). In consequence these five specific stakeholder groups are expected to affect CSR-related SDM. Hence: Hla: The greater the level of perceived shareholder pressure, the greater the likelihood that individual decision makers will decide to participate in the CSR activity of charitable donation.

H1b: The greater the level of perceived employee pressure, the greater the likelihood that the individual decision makers will decide to participate in the CSR activity of charitable donation.

H1c: The greater the level of perceived local government pressure, the greater the likelihood that individual decision makers will decide to participate in the CSR activity of charitable donation. 
H1d: The greater the level of perceived customer pressure, the greater the likelihood that individual decision makers will decide to participate in the CSR activity of charitable donation.

Hle: The greater the level of perceived competitor pressure, the greater the likelihood that individual decision makers will decide to participate in the CSR activity of charitable donation.

\section{Decision Context: Effects of Organizational Characteristics}

The role of CSR in SDM can vary considerably as a function of the organization's context. First, the industry in which an organization operates is known to influence CSRrelated decisions. Bhambri and Sonnenfeld (1988) compared the forest products industry with the insurance industry and found that the companies in each industry tended to engage in different CSR activities. In particular, they found that the direct ties linking forest products companies to particular customers and suppliers drove CSR interactions with specific external stakeholders. In contrast, due to the far more diverse portfolio of customers and intense regulation characterizing insurance, companies in this industry tended to be more politicized, that is, particularly sensitive to matters affecting external reputation. Insurance companies concentrated more on public stakeholders, such as government, non-governmental organizations (NGOs), and local communities.

In the present study, the salience of stakeholders is expected to differ by industry. In particular, the financial services industry in the Chinese context has broad public stakeholders, similar to the American insurance industry. Comparable to the forest products companies studied by Bhambri and Sonnenfeld (1988), contemporary Chinese firms in the mining and 
manufacturing industries each have their own stable base of specific customers (Jenkins and Yakovleva, 2006) as historically has been the case in manufacturing in the U.S. and other countries (Bhambri and Sonnenfeld, 1988). Accordingly, we hypothesize:

H2: Compared with manufacturing and mining industries, individual decision makers from the financial services industry will be more likely to decide to participate in the CSR activity of charitable donation.

The pattern of corporate control (i.e. public versus private ownership) has also played an important role in research on SDM. In particular, Lioukas et al. (1993) demonstrated that state-owned enterprises (SOEs) have privileged access to state resources compared with their non-SOE counterparts. Furthermore, SOEs can be required to conform to governmental directives. Because government is a salient stakeholder, SOEs can be pressured to act in ways consistent with the public interest, or at least in terms of how governmental stakeholders view public interest. Accordingly, we expect to find that the pattern of ownership will affect the relationship between stakeholder claims and individuals' decisions pertaining to the CSR activity of charitable donation. Hence:

H3: Individuals from state-owned enterprises will be more likely to decide to participate in the CSR activity of charitable donation than individuals from firms with a different ownership structure.

Past behavior is a strong predictor of future behavior, a core principle of social cognitive theory (Avey et al., 2010) and related schema theory conceptions of organizational decision processes (Hodgkinson and Healey, 2008). In particular, when individuals base decisions to behave in particular ways on their personal attitudes and beliefs, those behaviors are likely to 
recur (Aarts et al., 1998). Moreover, since each decision maker belongs to his or her own particular social network, their individual decisions will vary in part as a function of their unique observations of their work-related significant others' values at play. In keeping with this line of reasoning, Bowman and Moskowitz (2001) found that managers tended to adopt similar approaches in making CSR investment decisions to those which they observed among their peers and that they justified their decisions on the basis of those observations. Trevino (1986) observed a similar pattern of findings with regard to ethical decision making in firms. Colleagues in a given firm tended to display a high level of convergence and consistency over time with regard to the ethicality of their decisions. Trevino attributed these findings to the on-going influence of situational factors, arising from the job context and organizational culture. Hence:

H4: The greater the company's previous donation level, the greater the likelihood that the individual decision maker will participate in the CSR activity of charitable donation.

To participate effectively in CSR, firms must also possess the requisite slack resources, that is, funds, people or other resources not otherwise necessary to the firm's effective functioning. As firms grow, organizational decision makers have more access to such resources and are therefore more likely to partake in CSR-related activities (Johnson and Greening, 1999). Smaller firms more commonly face resource limitations, a factor that has been expected to constrain their involvement in CSR initiatives. In keeping with this reasoning, using the Fortune Corporate Reputation Index, Stanwick and Stanwick (1998) found that firm size has an adverse impact on CSR engagement. Accordingly, we hypothesize: H5: The greater the size of the firm, the more likely that the individual decision maker will 
decide to participate in the CSR activity of charitable donation.

Scholars have observed that the age of the firm is also an important factor that shapes CSR-related strategies. As firms evolve, different priorities and management practices take precedence. Early on, managers tend to concentrate on obtaining the requisite capital investment (Jawahar and McLaughlin, 2001). Hence, at that stage they may be less willing to partake in CSR activities as they lack the financial resources to do so. In contrast, mature firms are more likely to have the slack resources needed to engage in CSR-related activities and will thus be more likely to commit to doing so. We thus hypothesize:

H6: The greater the age of the firm, the more likely that the individual decision maker will decide to participate in the CSR activity of charitable donation.

The Decision Maker: Effects of Individual Characteristics

Individual attributes and beliefs, particularly those of the CEO, are known to impact on SDM (Hambrick and Mason, 1984). Indeed, across all managerial levels, personal values have been found to predict both the decision processes managers adopt and their choices (Sousa et al., 2010). Swanson (1995) offers an account of how managers' personal values shape their CSR-related decisions. She posited that managers driven largely by self-interest make decisions emphasizing organizational profits. In contrast, other-regarding managers make decisions emphasizing benefits to society (Hemingway and Maclagan, 2004; Swanson, 1995).

In this study we focus on two distinct types of values potentially important to CSR decision making. Self-enhancement focuses on personal success through achievement, and gaining social status, prestige, and dominance over people (Sagiv and Schwartz, 1995). Self- 
transcendence is its opposite, reflecting a concern for the welfare of others. When individuals' personal values emphasize self-enhancement, they tend to follow the self-interests level of moral reasoning. In contrast when their personal values align with the self-transcendence approach, they are more likely to use the other-regarding level of moral reasoning (Carroll, 1991). It is reasonable to assume that the self-interest level of moral reasoning leads individuals toward the lower levels of CSR, whereas the other-regarding level of moral reasoning leads them toward the higher levels of CSR activity. Feather (1995) found that selfinterest and other-orientation have opposing influences, and it is his operationalization that we use in this study (measuring the difference between the two values), which he terms "resultant self-enhancement". Hence:

\section{H7: The greater the level of resultant self-enhancement, the less likely that the individual} decision maker will decide to participate in the CSR activity of charitable donation.

The attitudes toward charity exhibited by the CEO tend to influence the decisions made by other stakeholders in the firm (Webb et al., 2000). This effect is consistent with the pervasive influence of other CEO attitudes (e.g., risk, achievement, competition, and innovation) on subordinates' decision making (Papadakis and Barwise, 2002). Hambrick and Mason (1984) provide an explanation of this phenomenon. Managers are required to acknowledge their organizational situations and consider the consequences attached to the various alternatives. As CEOs' attitudes have an impact on the consequences of decision making (Papadakis and Barwise, 2002), when particular individuals engage in SDM, they will consider their CEOs' attitudes, both to enlist their support and to avoid their objections. If the CEO's attitudes toward charity are perceived as positive, subordinate decision makers are 
more likely to support charitable donations, whereas CEO attitudes perceived as negative will diminish the decision maker's support. Hence:

H8: The greater the extent to which individual decision makers perceive that their CEOs' attitudes toward charity are favorable, the greater the likelihood that they will decide to participate in the CSR activity of charitable donation.

In sum, as depicted in Figure 2, a range of stakeholder, organizational and personal factors are likely to be incorporated in individuals' decisions to commit their firms to participate in the CSR activity of making charitable donations and the associated decision as to what might constitute the appropriate level of involvement.

\section{INSERT FIGURE 2 ABOUT HERE}

\section{Method}

\section{Sample \& Procedure}

A questionnaire was administrated to 830 participants of the EMBA, MBA, and executive training programs at seven prestigious universities in China. Seven experienced researchers assisted in the data collection. The response rate was $62.5 \%(519 / 830)$ and the valid response rate was $72.4 \%$ (376/519). Over half of the participants $(56.5 \%)$ were 35 years or older and $56.1 \%$ of the participants had more than 10 years tenure with their organization. The majority of the sample (71.3\%) held a bachelor's degree or higher-level qualification. Nearly two-thirds of the sample $(64.5 \%)$ was male and a similar proportion $(66.7 \%)$ was drawn from middle management or above. Among the sample, $36.4 \%$ were EMBA candidates, 
$19.7 \%$ were MBA candidates, and $43.9 \%$ were participants on senior executive training programs. Small (10-200 employees), medium (201-1500 employees), and large (above 1501 employees) firms each constituted about one third of the total sample. Roughly half of the participants (56.7\%) were employed by SOEs. A more complete profile of the background characteristics of the sample is reported in Table I.

\section{INSERT TABLE I ABOUT HERE}

\section{Development of the Survey Instrument}

In developing the survey instrument, we interviewed ten Chinese managers drawn from a range of industries. They provided useful suggestions regarding its length and the clarity of its instructions. The questionnaire was then translated into English and afterwards translated back into Chinese by two bilingual research assistants (Oreg et al., 2008). Issues identified were reconciled to ensure lexical, idiomatic, and grammatical-syntactical equivalence (Usunier, 1998). Participants in both the pilot study and the main study were unpaid volunteers with guaranteed anonymity.

Research Design and Measures

Design of the policy-capturing process. All participants were asked to make decisions in response to the same set of scenarios (Kachra and White, 2008). Each scenario combined different levels of each stakeholder variable (Karren and Barringer, 2002), referred to in PC studies as cues. For each participant their response values to each scenario (i.e., their decisions) were regressed on the response values of the various cues embedded in the 
scenarios. The resulting regression weights were used to indicate the degree to which the participants relied on each cue in making their decisions (Reeve et al., 2008), thus providing direct evidence of the actual influence the various stakeholder cues had on their decision making (Zhou and Martocchio, 2001).

The PC approach used here overcomes certain limitations of other research designs and knowledge elicitation techniques. Specifically, eliciting each individual's decisions using a set of scenarios with various combinations of cues is arguably more appropriate than asking them to rate each cue directly, on the grounds that they are unlikely to be sufficiently aware of their own cognitive processes to provide accurate ratings of the cues in question (Simon, 1990). Accordingly, in PC studies the actual weights a given decision maker applies to each cue are calculated. Another advantage of the PC method is that by manipulating experimentally the cues and their combinations researchers minimize high cue inter-correlations, thus avoiding the confounds and multi-colinearity often present in field studies (Rotundo and Sackett, 2002).

The PC design adopted enabled us to assess the influence of both within-participant and between-participant factors pertaining to each individual's decision (Zhou and Martocchio, 2001). Each scenario employed in the study centered on a major flood-related disaster spanning several geographical regions of China. The five within-participant components were claims from the five stakeholders (i.e. shareholders, employees, government, customers, and competitors), which were factorially crossed (Rotundo and Sackett, 2002). The various permutations of these cues enabled us to assess the independent effects of each stakeholder claim on the participants' CSR-related strategic decisions. With regard to stakeholder interests in disaster relief, there were three potential response options for each stakeholder: (1) 
supports, (2) does not support, and (3) does not care. However, in Chinese culture, those who do not support or do not care about charitable donation tend to keep silent to avoid being criticized for lack of generosity. Accordingly, the second and third alternatives were combined as ignore, thus resulting in a dichotomous independent variable $(1=$ supports versus $0=$ ignores) pertaining to each of the five cues, generating a total of thirty-two $\left(2^{5}=32\right)$ scenarios. The following scenario illustrates the main features of the thirty-two scenarios:

The shareholders, employees, local government, and customers pay no attention to firms' charity donation activities. However, a number of competitors have already made donations to the stricken areas.

In this example, shareholders, employees, the local government, and customers were coded as zero, whereas competitors were coded as one, yielding the following profile: $0,0,0$, 0,1 . After each scenario, the participants were asked to indicate the probability that they would make a donation on behalf of their organization at that moment in time.

The thirty-two scenarios were sufficient to obtain stable estimates of the participants' judgments, but risked fatiguing them in the process (Aiman-Smith et al., 2002). To strike a balance between obtaining sufficient information and overburdening the participants, we conducted a pilot test on ten Chinese Ph.D. students, each of whom had at least three years relevant work experience in China and was familiar with the issues we studied. This pilot test indicated that sixteen scenarios (i.e. half of those generated) were the maximum participants could complete without considerable fatigue. Also, we learned that holding constant the sequence of stakeholder claims across the varying combinations of cue levels helped reduce 
fatigue and sustain their interest. Accordingly we reduced the number of scenarios to sixteen, through an iterative process of random selection that ensured the subset of cue combinations retained for use yielded orthogonal responses, as PC requires (Zacharakis and Meyer, 1998).

Reliability and validity of the policy-capturing scenarios. In contrast to ways of establishing the validity of personal value and attitude instruments, the validity test of PC scenarios is more complicated. In accordance with Karren and Barringer (2002), the validity of PC scenarios was reinforced by asking ten Chinese Ph.D. students outside of China and ten Chinese managers in China to test the questionnaires. Based on the feedback they provided, the authors refined the scenarios and made them more realistic. Orlitzky et al. (2003) assert that this "self-report attribute design" promotes the external validity of results. We also tested for co-linearity among stakeholder variables. Results showed that the average variance inflation factor (VIF) was very close to 1, indicating co-linearity was not a problem (Bowerman and O' Connell, 1990) because random assignment achieved the desired distribution of uncorrelated cues across scenarios, as shown in Table II.

\section{INSERT TABLE II ABOUT HERE}

Using Kachra and White's approach to estimating the consistency and reliability of PC decisions, we conducted a factor analysis. It demonstrated that the PC decisions formed a single index, capturing nearly $60 \%$ of total variance and confirming the consistency with which our respondents made their decisions.

Decision responses. In line with previous PC studies (e.g., Hitt and Tyler, 1991), we 
employed 7- point Likert scales to indicate the likelihood that participants would consider their organization donating under each of the circumstances depicted. This measure provides the individual's self-reported beliefs regarding each stakeholder's importance to his or her charitable donation decision. It will be contrasted with the actual decision weights each stakeholder received in the policy capturing process.

Consistent with our hypothesis development above, industry, ownership, previous company donation, firm size, firm age, and the individual's personal values and their perceptions of their CEOs' attitudes toward charity were incorporated into the research design as between-participant independent variables. Participant age, gender, education, and current position were also assessed as control variables (cf. Hambrick and Mason, 1984).

Personal values. Our measurement of personal values was operationalized using the Schwartz Value Survey (SVS), an inventory demonstrated to have cross-national application, including Eastern and Western cultures (Schwartz, 1992). The SVS comprises 57 items, which form 10 value types (i.e., universalism, benevolence, conformity, tradition, security, power, achievement, hedonism, stimulation, and self-direction). Schwartz (1992) postulates that the ten value types fall into four higher-order value domains, namely, self-transcendence, conservation, self-enhancement, and openness-to-change. Self-enhancement and selftranscendence values demonstrate closer relevance to CSR-related decisions compared with conservation and openness-to-change (McWilliams et al., 2006). Some SVS items were thus omitted because they pertain to domain specific issues that lie beyond the purview of the present study (cf. Sousa and Bradley, 2006). In total, 12 self-enhancement and 13 selftranscendence items were incorporated in the study and the participants were required to 
assess each value statement according to its importance as a guiding principle in their lives. In line with the instrument originators' instructions, each of the value statements was evaluated on a 9-point Likert scale ranging from (-1) “opposed to my values", through (0) "not important" to (7) “of supreme importance”. Following Feather (1995), we derived the resultant self-enhancement measure by subtracting the mean score of two self-transcendent values (i.e., universalism and benevolence) from the mean score of three self-enhancement values (i.e., power, achievement, and hedonism). The Cronbach's alpha coefficients for selftranscendence and self-enhancement were .86 and .76 respectively, indicating good reliability (Nunnally, 1978).

Perceptions of CEOs'attitudes toward charity. To assess the participants' perceptions of their CEOs' attitudes toward charity, we adapted the nine-item instrument devised by Webb et al. (2000). This particular instrument was selected on the grounds that it has been well validated and is widely accepted as such in the literature (see, e.g., Venable et al., 2005). Four of the items tap attitudes toward charity in general, while the remaining five tap attitudes toward charitable organizations. For present purposes, however, the item wording was modified slightly to reflect participants' perceptions of their CEOs' attitudes; and responses to all nine items were summed to form an overall assessment of attitudes toward charity. The rationale for combining the 9 items into a unified scale is that, in the Chinese context, if people want to donate, they can only do so through recognized charitable organizations, such as the Red Cross. Accordingly, we reasoned that it would be conceptually meaningless to treat the two facets as separate constructs in the present study. The Cronbach's alpha for this modified scale (hereinafter referred to as attitudes toward charity) was .76, indicating good 
reliability (Nunnally, 1978).

Approach to PC Analysis

We examined the PC data with MLwiN (version 2.24), a professional software package for the analysis of multilevel and nested models (Rasbash et al., 2009). The major difference between MLwiN and HLM (Zhou et al., 1999), a commonly employed alternative approach for analyzing multilevel and nested data typical of the sort obtained in PC studies, is that the core estimation technique of MLwiN is interactive generalized least squares (IGLS), whereas HLM is based on ordinary least squares (OLS). The latter is a less efficacious estimation procedure, known to be error prone and hence biased in comparison with the IGLS estimation technique underpinning MLwiN (Rasbash et al., 2009). Not surprisingly, the MLwiN approach has gained increasing popularity in applied psychology in recent years (e.g., Sonnentag et al., 2008). Furthermore, as we have five within-participants factors (stakeholders) and seven between-participants factors, it is more feasible to examine the data with MLwiN, which automatically calculates the interactions between variables during estimation. For both of these reasons, MLwiN was the approach of choice.

For the multilevel model, both main effects and interactions among the variables were estimated (Rasbash et al., 2009) in a two-step process. In Step 1, we regressed each scenario score on the five sets of stakeholder cues to test H1. The resulting standardized regression coefficients were used to ascertain each cue's average importance across the sixteen scenarios. In Step 2, we examined the influence of the organizational and individual characteristics on the decision to make charitable donations in order to test $\mathrm{H} 2$ through $\mathrm{H} 8$. 


\section{Results}

Descriptive statistics for the study variables (Table III) show that resultant self-

enhancement, CEOs' attitudes toward charity, firm size, firm age, company previous donation, and industry were correlated significantly $(P<.05)$ with the overall scenario scores. In contrast, the dummy variable SOE was unrelated to the scenario scores (further analysis confirming this conclusion is reported in Step 2 of the PC analysis below). Scenario scores were uncorrelated with the participants' age, gender, education, current position, or work experience. Hence, there is no need to control for these variables in subsequent analyses.

\section{INSERT TABLE III ABOUT HERE}

The split-record method of MLwiN tested the two-level nested model described above. The 16 scenarios were classified at the within-participant level, while the organizational and individual characteristics were classified at the between-participant level, yielding a total of 6,016 observations (376 participants X 16 scenarios).

PC Analysis: Step 1

To test all elements of $\mathrm{H} 1$, we conducted a regression analysis of the scenario scores on the cues pertaining to each of the five stakeholders. Estimates of the average intercepts and slopes across each scenario are reported in Table IV. The average intercept $\left(5.01^{* * *}\right)$ was significantly different from zero (intercept $\mathrm{t}=84.86,{ }^{* * *} \mathrm{p}<.001$ ). The average slope coefficients for shareholders $\left(.08^{*}\right)$, employees $\left(-.09^{* *}\right)$, government $\left(.22^{* * *}\right)$, customers $\left(.37^{* * *}\right)$, and competitors $\left(.11^{* * *}\right)$ all differed significantly from zero. The positive effects of 
the shareholder, government, customer, and competitor cues indicate that as levels of stakeholder claims increase, the likelihood of participants' decisions to donate rises, consistent with H1a, H1c, H1d, and H1e. However, the significant negative sign for the employee cue indicates that as employee claims increase, the likelihood of participants deciding to donate decreases in contrast to our expectations. Consequently, $\mathrm{H} 1 \mathrm{~b}$ is rejected.

\section{INSERT TABLE IV ABOUT HERE}

To examine their relative effects, we assessed the variance explained by each cue (i.e. the results reported in last three columns of Table IV). IGLS calculates both the main effects and interactions among the variables. Our results show that taking all of the five stakeholders' claims together, the most important are shareholders and the local government. For every unit increase in shareholder expectations there is a corresponding . 31 unit of increase in the aggregated scenario score. Similarly, for every unit increase in government claims, there is a corresponding .15 unit increase in the aggregated scenario score. The customers and employee cues each separately correspond to a .07 unit increase in the scenario score. The competitor cue had no effect when considered with the other stakeholder cues. We also calculated the $\mathrm{R}^{2}$ value explained by the five stakeholder cues, as the total variance (i.e., the total variance of the two levels explained by the null model) minus the total residual variance of the five predictors, divided by the total variance (Kristof-Brown et al., 2002). Effect sizes of the five stakeholder claims accounted for $64.5 \%$ in total, indicating that variance in the dependent variable is well accounted for by these five cues. Running the null model, we 
calculated that the variance explained by the scenario level (i.e., the varying claims of shareholders, employees, governments, customers, and competitors) is $74.8 \%$, with the between-person variables studied accounting for the $25.2 \%$.

PC Analysis: Step 2

We hypothesized that industry (financial services versus manufacturing and mining), firm ownership (state-owned enterprise versus non-state-owned enterprise) previous company donation, firm size, firm age, and perceived CEOs' attitudes toward charity would each exhibit positive effects, whereas participants' resultant self-enhancement was expected to have a negative effect on their charitable donation decisions. To test these hypotheses, we regressed the five stakeholder claims and the relevant organizational and individual characteristics on the dependent variable (see Table V). Since industry (financial services versus manufacturing and mining), previous company donation, firm size, firm age, and CEOs' attitudes toward charity were each positively related to the decision to donate, $\mathrm{H} 2, \mathrm{H} 4$, H5, H6, and H8 were all supported. Furthermore, since resultant self-enhancement was negatively related to the dependent variable, $\mathrm{H} 7$ was also supported. However, the influence of firm ownership (state-owned enterprise versus non-state-owned enterprise) was nonsignificant; contrary to expectations, participants from SOEs were no more likely to donate than their non-SOE counterparts and $\mathrm{H} 3$ was thus rejected.

\section{INSERT TABLE V ABOUT HERE}

Table V reports our analysis of the joint effects of the within-participant scenario level 
and between-participant individual level factors in concert. The regression coefficients pertaining to the shareholder, government, customer, and competitor cues were all significant and positive, while the significant coefficient pertaining to employees was negative. In addition, firm age, previous company donation, and CEOs' attitudes toward charity each had a significant positive impact on the donation decision. For each regression, the employee coefficient remained negative, indicating that employee claims were correlated negatively with the participants' inclination to make charitable donations on behalf of the firm. The effect size was computed for each organizational and individual characteristic; that is, the total variance explained by the null model minus the variance not contributed to by the five stakeholders and the focal organizational or individual characteristics, divided by the total variance available (Kristof-Brown et al., 2002). Previous company donation explains $4.1 \%$ of the variance in the dependent variable. The effect sizes of the other variables (i.e., industry, firm size, firm age, personal values, and CEOs' attitudes toward charity) are relatively small, thus indicating that those variables at best had slight influence on the participants' decisions. As noted earlier, only $25.2 \%$ of the total variance in the dependent variable was available to be explained by the organizational and individual characteristics; hence, not surprisingly the observed effects were modest.

Comparing Actual Stakeholder Decision Weights to Perceived Weights

Our finding that employee claims had a negative impact on donation decisions is intriguing, not least because it runs counter to prior theory and research (Trevino, 1986). We were able to further investigate this paradox by examining the participants' self-reported use of stakeholder claims in their decisions. Based on the question "when you make decisions 
about charity donations for your organization, to what extent do you focus on the following stakeholders...", utilizing a 7-point Likert scale we obtained the following mean ratings by the participants of each stakeholder's salience to the donation decision: shareholders (5.62), employees (4.96), customers (5.38), government (5.38), and competitors (5.04). Consistent with their actual use of stakeholder claims in their decisions, participants identified shareholders and government as the most salient stakeholders. In contrast, their ratings of competitors on this question are clearly out-of-line with the absence of a competitor effect when other claims are entered into the model predicting scenario scores. The low ratings pertaining to employees may be more consistent with our participants' actual negative use of employee claims in making donation decisions. Thus participants seem to have some, albeit incomplete, awareness of the actual cognitive representations they employ in making donation decisions.

\section{Discussion}

The primary aim of the present study was to analyze the structure and content of the revealed decision processes used by decision makers regarding corporate charitable donations. It demonstrates that CSR-related strategic decisions concerning charitable donations can be influenced by stakeholder claims as well as by organizational and individual characteristics. Although Agle et al. (1999) and Brammer and Millington (2004) examined the relationship between organizational characteristics and CSR activities, they did not investigate other influential factors (e.g., CEO attitudes and previous donation activity). The present study has provided a more complete perspective by examining CSR issues from a cognitive perspective and in so doing it has offered a novel empirical contribution to stakeholder theory. 
Overall, our findings indicate that the Chinese organizational decision makers studied are disposed favorably to making CSR-related charitable donations. Given that a scenario score of 4 represents a neutral response, the fact that we obtained a mean score of 5.43 , based on a total of 6,016 observations indicates clearly that the overwhelming majority of participants would be likely to donate on behalf of their organizations. This encouraging finding may be a reflection of the prevailing Chinese moral philosophy.

Confucian culture advocates that people should pursue their own self-development while also benefitting others in the society. Philanthropy, benevolence, and humility are values embedded in traditional Chinese culture (Gao, 2010). At the same time, China is a collectivist country, in which individuals make concerted efforts to cooperate, support the larger whole, and maintain harmony (Zhou and Martocchio, 2001). People appear to be inclined to help the poor or victims of disasters, as in the case of the aforementioned Great Wenchuan Earthquake that occurred on May $12^{\text {th }}, 2008$, when individuals and companies in large numbers made donations to support those in the affected disaster areas. As further illustration, Shenzhen Stock Market -listed companies are encouraged to follow the "Social Responsibility Guidelines for Listed Companies" and to report their CSR activities (Gao, 2010).

Although the above explanation is context-specific, our findings also support a broader account of organizational decision making pertaining to charitable donation, one that portrays decision makers as boundedly rational (Simon, 1956), driven variously by a combination of stakeholder claims and a range of organizational and individual factors, in a manner consistent with the theoretical model we outlined. Of the five stakeholders we examined, both shareholder and government claims had positive effects on participants' strategic decisions 
pertaining to charitable donation, explaining the majority of the variance in the decisions studied. This finding is consistent with Nenova's (2003) observation that in China only the most powerful stakeholders have decision rights and can influence the strategic decision process.

Previous studies indicate that Chinese firms with political ties donate more than firms without connections with local government (Gao, 2010), highlighting the government's power in corporate charitable donations. Political connections provide firms with crucial access to policymakers, scarce resources, and favorable treatment by powerful external stakeholders (Sheng et al., 2011). Businesses take philanthropic disaster relief as an opportunity to display their social conscience; in so doing they satisfy the demands of local governments and develop good guanxi with them (Gao, 2010). We note that "The Company Law of the People's Republic of China (2006 revision)" makes the provision that companies should participate in charitable donation in "a proper way." Although it does not specify the proper ways to do so, nonetheless, this legislation serves to legitimate CSR activities.

Our findings revealed that customer and competitor claims had far less effect than the institutional pressure of government and shareholders. The low impact of customer claims differs from the findings of previous research linking CSR activities with attempts to build brand dominance (Berens et al., 2005) and customer loyalty (Luo and Bhattacharya, 2006). However, such effects are likely to be pronounced in larger firms (Sen et al., 2006). In contrast, the present study investigated managers drawn largely from small and medium enterprises, as defined in accordance with the enterprise classification of the National Bureau of Statistics of China. Hence, as a caveat we acknowledge that the firms sampled might have 
been too small to attract significant customer attention by making corporate charitable donations.

Competitor claims similarly played only a small role in our participants' donation decisions. A potential factor in this regard could be the fact that CSR in China plays a different role as compared to the West. Porter and Kramer (2006) note that Western firms utilize philanthropy as a differentiation strategy, making it effective only when competitors fail to make similar levels of ethical investment. In China, in contrast, firms that do not provide societal benefits comparable to those of their competitors may become targets of public criticism. In the Wenchuan Great Earthquake, Wang Laoji (a beverage company) took the very first step to donate more than a hundred million RMB (circa 1.5 million U.S. dollars). In contrast, other beverage companies, such as Wa Haha and Coca Cola failed to donate as much and subsequently were criticized heavily in the media. Hence, if a normative standard promoting charitable donation during disaster relief exists, any differentiation opportunity to be gained by donating is limited.

Our findings regarding the negative impact of employee claims are perhaps the most striking. A potential explanation of these intriguing findings is that Chinese culture is characterized by high power distance making managers less inclined to respond to the opinions of subordinates (Tse et al., 1997). The unmeasured role of unionization is an additional factor. In the context of unionized firms, managers may not view themselves as representing their employees' concerns. Trade unions in China are expected to act on behalf of employees with respect to charitable donations (Clarke, 2005). It may be the case, therefore, that managers in unionized firms cede the response to employee claims regarding CSR to 
unions. Since unionization was not measured, we cannot test this explanation, but the lack of responsiveness in the actual decisions made to employee claims warrants attention given the inconsistency of this finding in comparison with research in the West.

Organizational decision makers have relatively limited time, energy, and access to information (Hambrick and Mason, 1984; Simon, 1956). Accordingly, relationships across the diverse range of stakeholders are not managed with equal attention. Moreover, managers may not even recognize the strategic importance of some stakeholders (Mitchell et al., 1997). In stakeholder salience theory, those stakeholders who possess all three of the characteristic attributes of legitimacy, power, and urgency are regarded as highly salient stakeholders, whose claims ultimately determine the ensuing corporate strategy. In our study, shareholders and government were in this position. Meanwhile, those stakeholders who possess only one or two of the defining attributes are latent stakeholders; as such, they may not have a direct impact on, or even any meaningful say in, the strategic decision process at present. They may, however, become influential in due course, by attaining the additional requisite attributes (Mitchell et al., 1997).

Our results also affirm prior theory and research regarding the organizational factors that influence individuals' CSR-related strategic decisions concerning charitable donation (Brammer and Millington, 2004; Gao, 2010). Previous company donation, firm size, and firm age all had positive effects. Also in line with our theorizing, we found that participants from the financial services industry were more likely to make decisions to engage in CSR activities than participants from the manufacturing and mining industries (Brammer and Millington, 2004). Corporate charitable donations by SOEs are driven largely by government direction. 
Foreign owned enterprises (FOEs) with significant concerns for managing their legal and political position in the larger society are more likely to focus on improving the local community through philanthropy (Brammer et al., 2009). In the present study, more than $77 \%$ of the FOEs incorporated in our sample (still a small portion of the sample as a whole) were medium or large firms, subject to public and media attention. The non-SOEs incorporated in the present study included both private enterprises and FOEs. Note, however, that ownership effects have not been found consistently in previous CSR studies, suggesting there may be unmeasured moderating factors underlying the role of ownership in CSR (Brammer and Millington, 2004; Gao, 2010).

Personal values were the primary individual variable studied here that contributed to decisions regarding charitable donations on behalf of the firm. Similar to evidence from the U.S. (Agle et al., 1999), we found that managers motivated by self-enhancement were less likely to decide to donate their firms' money to charity. This finding is in line with previous research on the effects of altruism and egotism on CSR activities (McWilliams et al., 2006).

CEOs' attitudes toward charity were associated positively with the participants' decisions regarding charitable donation. Two factors may have contributed to this relationship. First, CEOs might be more inclined to donate to charitable organizations due to strategic or expressive reasons that are understood and shared by their subordinates (Bundy, Shropshire and Buchholz, 2013). This factor may have led the individuals we studied to make donation decisions consistent with their CEO's attitudes. Second, individuals may be inclined to make decisions consistent with their CEOs' attitudes because such commensurate decisions are likely to be approved, not least because conformity to CEO opinion is in line with the 
hierarchical nature of most Chinese enterprises (Adler et al., 1989).

\section{Research Implications}

Our findings from China indicate that the influential stakeholders in the minds of organizational decision makers may not always be the ones that (Western) scholars believe them to be. Previous research centered on CSR-related decision making has focused largely on the influence of shareholders (McWilliams and Siegel, 2001) and customers (Luo and Bhattacharya, 2006). Such effects are consistent with the notion that Western managers seek to maximize shareholder wealth and make a profit by satisfying customer needs (Poitras, 1994). In contrast, our findings reveal a dominant role played by both shareholders and government in the minds of Chinese organizational decision makers. These results suggest that some of the fundamental axioms of the highly influential stakeholder theory of CSR decision making are ripe for rethinking. At minimum, scholars need to acknowledge that the stakeholders traditionally considered important in the West may well play rather different roles in the minds of managers in China and elsewhere.

Bundy, Shropshire and Buchholz (2013) observe that stakeholder salience reflects both strategic interests (access to resources and legitimacy) and expressive concerns (consistency with corporate identity). An important research question is the capability of firms in developing economies to use socially complex practices such as corporate identity or corporate culture. These practices differentiate firms based on values, and CSR is closely tied to expressive as well as strategic concerns. Although market-oriented management practices have burgeoned in recent years, due to Chinese economic reforms, the expressive, valueoriented practices that differentiate firms based on culture and identity may be less well 
developed. This is particularly likely to be the case for smaller firms less in the public eye. In that respect other stakeholders may become more salient over time as economic development continues, particularly if corporate culture and identity are leveraged to grant legitimacy to employee claims. Relatedly, given the small effect size associated with firm size, although managers in small firms might feel themselves constrained in engaging in CSR initiatives, if well-crafted and approached holistically as part of a wider package of strategic and expressive corporate concerns, CSR initiatives can actually reduce costs (cf. Bundy, Shropshire and Buchholz, 2013).

More generally, our findings affirm those of Fu and colleagues (2010) regarding the importance of enacted values (self-effacing vs. self-enhancing) of decision makers occupying varying positions. The nature of the influence is expected to depend on the congruence between the leader's own values and his or her transformational behavior. One issue for further study, therefore, is the process(es) through which leaders' CSR-oriented values influence the behavior of subordinates. In particular, it will be most informative to discover whether the effects of leadership are direct ones, or a function of an interaction between the leader's values and/or behavior with the values and/or behavior of the individual subordinate. Moral leadership is thus clearly an important topic for future research.

\section{Implications for Practice}

The current study enhances understanding of the cognitive basis of individuals' decision processes pertaining to CSR-related issues and calls attention to several practice concerns. Participants in firms where the CEO valued charitable activities were more likely to make the decision to donate. Decision makers throughout the organization are likely to take a cue from the values and behavior of the firm's top executive. CSR activities and the firm's strategy are 
likely to be better aligned, therefore, when the CEO makes clear to other senior leaders the basis of his or her own CSR-related decisions. Such cues may be especially important in firms with multiple stakeholders (in contrast to firms with a limited set of key stakeholders). CSR-related opportunities in firms with many stakeholders are likely to be diverse and more difficult to recognize and respond to appropriately. Establishing general principles based on strategy or core values can bring coherence to the organization's CSR practices.

Given that the findings from the present Chinese sample differ in notable ways from what has been found in the West, our study calls attention to the fact that the influential stakeholders in the minds of Chinese organizational decision makers may not be what their Western counterparts believe them to be. Such cross-country differences may yield important information for expatriate managers new to China as well as for inexperienced managers who may not have a clear map of relevant stakeholders in their firm's specific context. Accordingly, we suggest that expatriate training and development incorporate education regarding those stakeholders Chinese managers view as relevant to their organizations, together with the cultural and institutional factors underlying these views.

Nonetheless, we note that the salience of stakeholders can change with time (Mitchell et al., 1997). Although employees, customers, and competitors may not influence the present, those same stakeholders over time could adopt a range of approaches such as engaging the media or lobbying for new regulations to enable them to become salient stakeholders and thus influence the firm in due course. Such latent stakeholders may exploit other tactics to impress their interests on the firm's strategy (Mitchell et al., 1997). For instance, customers may use the power of social media (e.g., Kaixin Wang, the Chinese version of Facebook or Wei Bo, the 
Chinese version of Twitter) to express their views pertaining to particular companies' CSRrelated activities, in turn causing the companies in question to reflect more deeply on the social consequences of their behavior (Porter and Kramer, 2006). Hence, managers need to keep an open mind regarding the identity and influence of their firms' stakeholders, recognizing that their beliefs may not always be accurate or unbiased.

\section{Limitations}

There are several potential limitations to the present study. First, as PC techniques only allow the analysis of a specific issue, in this study we have concentrated on charitable donation, without considering other potentially salient CSR issues (e.g., environmental management, product safety).

Second, our simplified scenario design may have reduced the cognitive burden on participants to the point that they were able to consider more factors in their decisions than they would ordinarily in the hustle and bustle of everyday organizational life. Our decision to focus on stakeholders and other factors the existing literature highlights inevitably means that we overlooked other potentially relevant influences such as social media. On the other hand, Yin and Zhang (2012) found that stakeholders such as 'the community' play little role in motivating Chinese companies to engage in CSR activities, consistent with their omission here.

Third, our sample of Chinese organizational decision makers was derived from a sampling frame composed of EMBA and MBA students and participants in executive education, a factor that might lead some scholars to question its appropriateness for gaining the insights desired from the reported study. However, a close examination of data pertaining 
to the background characteristics of the three subgroups germane to our hypotheses did not reveal any differences of substantive concern. Nonetheless, it remains a possibility that some of our participants may not actually have experience of making CSR decisions in their own firms.

Fourth, although our categorization of 'Previous donation' $(0=$ lower level $\leq 1$ million RMB and 1=higher level > 1 million RMB ) was in line entirely with Zhang et al.'s (2010) aforementioned study, which found that the mean and median of corporate contributions in response to the Sichuan earthquake for the 703 Chinese firms studied were 3,086,688 and 1,001,000 RMB respectively, in hindsight the highest factor level for the 'previous donation' factor, was perhaps excessively high; as such, it may have been confounded with 'firm size'. In future work, therefore, perhaps a better variable might be 'contribution level per employee'.

Finally, in the present study there were five within-participants factors and seven between-participants factors, thus making analysis of cross-level interactions difficult. Nonetheless, our findings provide the first investigation of the decision processes individuals engage in with regard to CSR, and our findings are largely consistent with theory. At the same time, our findings have extended the analysis of CSR to the Chinese context and provided an important first look inside the black box of corporate decision making in this developing economic system.

Although the present study demonstrates the impact of several theoretically important organizational and individual factors, further work is required to investigate the influence of a wider range of variables, not least organizational financial performance, corporate reputation, and the extent and nature of decision makers' political connections. The present line of work 
could also be extended profitably to examine a wider range of CSR-related issues, beyond charitable donation per se, in an attempt to derive a more complete account of the contextual and individual factors that influence this important class of organizational decisions and the generative mechanisms underpinning them. Moreover, it will be interesting to conduct field studies to investigate the extent to which the actual behavior of CSR decision makers in Chinese Companies mirrors the outcomes of the present work.

\section{Conclusion}

This study has contributed to the CSR literature in general and to stakeholder salience theory in particular by providing several new insights into the phenomenon of charitable donation. First, it has demonstrated that some of the traditional stakeholders associated with CSR may not be as influential as commonly believed. In contrast with Western economies, shareholders and government are the most salient stakeholders in the Chinese context studied here. Second, a range of organizational (previous corporate charitable donations by the firm, its size, ownership, industry, and age) and individual (personal values and perceptions of the CEO's attitudes toward charity) factors have been shown to each influence individuals' decisions regarding whether or not to make a charitable donation on the organization's behalf. In particular, the personal value of self-enhancement has been shown to reduce the likelihood that decision makers will endorse the making of corporate donations, thus indicating that personal selfishness likely constrains CSR activities. Finally, our findings suggest that employee stakeholders may play a heretofore unrecognized and complicated role in the minds of decision makers. In all, our findings offer an insightful first glimpse inside the black box of organizational decision making pertaining to corporate social performance. 


\section{References}

Aarts, H., Verplanken, B. and van Knippenberg, A. (1998). Predicting behavior from actions in the past: Repeated decision making or a matter of habit? Journal of Applied Social Psychology 28(15), 1355-1374.

Adkins, C. L., Russell, C. J. and Werbel, J. D. (1994). Judgments of fit in the selection process: The role of work value congruence. Personnel Psychology 47(3), 605-623.

Adler, N. J., Campbell, N. and Laurent, A. (1989). In search of appropriate methodology: From outside the People's Republic of China looking in. Journal of International Business Studies 20(1), 61-74.

Agle, B. R., Mitchell, R. K. and Sonnenfeld, J. A. (1999). Who matters to CEOs? An investigation of stakeholder attributes and salience, corporate performance, and CEO values. Academy of Management Journal 42(5), 507-525.

Aguilera, R. V., Rupp, D. E., Williams, C. A. and Ganapathi, J. (2007). Putting the S back in corporate social responsibility: A multi-level theory of social change in organizations. Academy of Management Review 32(3), 836-863.

Aiman-Smith, L., Scullen, S. E. and Barr, S. H. (2002). Conducting studies of decision making in organizational contexts: A tutorial for policy-capturing and other regression-based techniques. Organizational Research Methods 5(4), 388-414.

Avey, J. B., Luthans, F. and Youssef, C. M. (2010). The additive value of positive psychological capital in predicting work attitudes and behaviors. Journal of Management 36(2), 430-452. 
Berens, G., Riel, C. B. M. and Bruggen, G. H. (2005). Corporate associations and consumer product responses: The moderating role of corporate brand dominance. Journal of Marketing 69(3), 35-48.

Bhambri, A. and Sonnenfeld, J. (1988). Organization structure and corporate social performance: a field study in two contrasting industries. Academy of Management Journal 31(3), 642-662.

Bowerman, B. L. and O' Connell, R. T. (1990). Linear statistical models: An applied approach (Second edition). Belmont, CA: Duxbury Press.

Bowman, E. H. and Moskowitz, G. T. (2001). Real options analysis and strategic decision making. Organization Science 12(6), 772-777.

Brammer, S. J. and Millington, A. (2004). The development of corporate charitable contributions in the UK: A stakeholder analysis. Journal of Management Studies 41(8), 1411-1434.

Brammer, S. J., Pavelin, S. and Porter, L. A. (2009). Corporate charitable giving, multinational companies and countries of concern. Journal of Management Studies 46(4), 575-596.

Bundy, J., Shropshire, C., Buchholz, A.K. (2013). Strategic cognition and issue salience: Toward an explanation of firm responsiveness to stakeholder concerns. Academy of Management Review 38 (3), 352-376.

Buysse K and Verbeke A. (2003). Proactive environmental strategies: A stakeholder management perspective. Strategic Management Journal 24(5), 453-470.

Carroll, A. B. (1991). The pyramid of corporate social responsibility: toward the moral 
management of organizational stakeholders. Business Horizons 34(4), 39-48.

Chapple, W. and Moon, J. (2005). Corporate social responsibility in Asia. Business \& Society 44(4), 415-441.

Churchill, Jr. G. A. and Peter, J. P. (1984). Research design effects on the reliability of rating scales: a meta-analysis. Journal of Marketing Research 21(4), 360-375.

Clarke, S. (2005). Post- socialist trade unions: China and Russia. Industrial Relations Journal 36(1), 2-18.

DiMaggio, P. J. and Powell, W. W. (1983). 'The Iron Cage Revisited: Institutional Isomorphism and Collective Rationality in Organizational Fields'. American Sociological Review 48(2), 147-160.

Driscoll, C. and Starik, M. (2004). The primordial stakeholder: advancing the conceptual consideration of stakeholder status for the natural environment. Journal of Business Ethics 49(1), 55-73.

Edwards, J. R. and Cable, D. M. (2009). The value of value congruence. Journal of Applied Psychology 94(3), 654-677.

Elbanna, S. and Child, J. (2007). The Influence of Decision, Environmental and Firm Characteristics on the Rationality of Strategic Decision Making. Journal of Management Studies 44(4), 561-591.

Erdogan, B., Kraimer, M. L. and Liden, R. C. (2004). Work value congruence and intrinsic career success: The compensatory roles of leader-member exchange and perceived organizational support. Personnel Psychology 57(2), 305-332.

Feather, N. T. (1995). Values, valences, and choice: The influences of values on the perceived 
attractiveness and choice of alternatives. Journal of Personality and Social Psychology 68(6), 1135-1151.

Fu, P., Tsui, A. S., Liu, J., and Li, L. (2010). Pursuit of whose happiness? Executive leaders' transformational behaviors and personal values, Administrative Science Quarterly 55, $222-254$.

Gao, Y. (2011). Philanthropic disaster relief giving as a response to institutional pressure: Evidence from China. Journal of Business Research 64(12), 1377-1382.

Garriga, E. and Melé, D. (2004). Corporate social responsibility theories: mapping the territory. Journal of Business Ethics 53(1-2), 51-71

Hambrick, D. C. (2007). Upper echelons theory: An update. Academy of Management Review 32(2), 334-343.

Hambrick, D. C and Mason, P. A. (1984). Upper echelons: The organization as a reflection of its top managers. Academy of Management Review 9(2), 193-206.

Harrison, J. S., Bosse, D. A. and Phillips, R. A. (2010). Managing for stakeholders, stakeholder utility functions, and competitive advantage. Strategic Management Journal 31(1), 58-74.

Hemingwa, C. A. and Maclagan, P. W. (2004). Managers' personal values as drivers of corporate social responsibility. Journal of Business Ethics 50(1), 33-44.

Hitt, M. A. and Tyler, B. B. (1991). Strategic decision models: Integrating different perspectives. Strategic Management Journal 12(5), 327-351.

Hodgkinson, G. P. and Healey, M. P. (2008). Cognition in organizations. Annual Review Psychology 59, 387-417. 
Jawahar, I. M. and McLaughlin, G. L. (2001). Toward a descriptive stakeholder theory: An organizational life cycle approach. Academy of Management Review 26(3), 397-414.

Jenkins, H. and Yakovleva, N. (2006). Corporate social responsibility in the mining industry: Exploring trends in social and environmental disclosure. Journal of Cleaner Production 14(3-4), 271-284.

Johnson, R. A. and Greening, D. W. (1999). The effects of corporate governance and institutional ownership types on corporate social performance. Academy of Management Journal 42(5), 564-576.

Joyner, B. E. and Payne, D. (2002). Evolution and implementation, a study of values, business ethics and corporate social responsibility. Journal of Business Ethics 41(4), 297-311.

Judge, T. A. and Bretz, R. D. (1992). Effects of work values on job choice decisions. Journal of Applied Psychology 77(3), 261-271.

Kachra, A. and White, R. E. (2008). Know how transfer: the role of social, economic/competitive, and firm boundary factors. Strategic Management Journal 29(4), 425-445.

Karren, R. J. and Barringer, M. W. (2002). A review and analysis of the policy-capturing methodology in organizational research: Guidelines for research and practice. Organizational Research Methods 5(4), 337-361.

Kristof-Brown, A. L., Jansen, K. J. and Colbert, A. E. (2002). A Policy-Capturing Study of the Simultaneous Effects of Fit With Jobs, Groups, and Organizations. Journal of Applied Psychology 87(5), 985-993.

Li, W. and Zhang, R. (2010). Corporate social responsibility, ownership structure, and 
political interference: Evidence from China, Journal of Business Ethics 96(4), 631-645.

Lioukas, S., Bourantas, D. and Papadakis, V. (1993). Managerial autonomy of state-owned enterprises: Determining factors. Organization Science 4(4), 645-666.

Luo, X. and Bhattacharya, C. B. (2006). Corporate social responsibility, customer satisfaction, and market value. Journal of Marketing 70(4), 1-18.

Marrewijk, M. V. (2003). Concepts and definitions of CSR and corporate sustainability: between agency and communion. Journal of Business Ethics 44(2-3), 95-105.

McWilliams, A. and Siegel, D. (2000). Corporate social responsibility and financial performance: correlation or misspecification? Strategic Management Journal 21(5), 603-609.

McWilliams, A. and Siegel, D. (2001). Corporate social responsibility: A theory of the firm perspective. Academy of Management Review 26(1), 117-127.

McWilliams, A., Siegel, D. S. and Wright, P. M. (2006). Corporate social responsibility: strategic implications. Journal of Management Studies 43(1), 1-18.

Mitchell, R. K., Agle, B. R. and Wood, D. J. (1997). Toward a theory of stakeholder identification and salience: Defining the principle of who and what really counts. Academy of Management Review 22(4), 853-886.

Mujtaba, B. G. (2010). Strategic philanthropy and maximization of shareholder investment through ethical and values-based leadership in a post Enron/Anderson debacle. Journal of Business Studies Quarterly 1(4), 94-109.

Nenova, T. (2003). The value of corporate voting rights and control: A cross-country analysis. 
Journal of Financial Economics 68(3), 325-351.

Nunnally, J. C. (1978). Psychometric Theory (2 ${ }^{\text {nd }}$ Edition). New York: McGraw-Hill.

Nutt, P. C. (2004). Expanding the search for alternatives during strategic decision making. Academy of Management Executive 18(4), 13-28.

Oreg, S., Bayazit, M., Vakola, M., Arciniega, L., Armenakis, A. and Barkauskiene, R. et al. (2008). Dispositional resistance to change: measurement equivalence and the link to personal values across 17 nations. Journal of Applied Psychology 93(4), 935-944.

Orlitzky, M., Schmidt, F. L. and Rynes, S. L. (2003). Corporate social and financial performance: A meta-analysis. Organization Studies 24(3), 403-441.

Papadakis, V. M. and Barwise, P. (2002). How much do CEOs and top managers matter in strategic decision making? British Journal of Management 13(1), 83-95.

Pfeffer, J. (1981). Power in organizations. Marshfield: Pitman.

Poitras, G. (1994) Shareholder wealth maximization, business ethics and social responsibility. Journal of Business Ethics 12(2), 125-134.

Porter, M. E. and Kramer, M. R. (2006). Strategy and society. Harvard Business Review 84(12), 78-92.

Rasbash, J., Steele, F., Browne, W. J. and Goldstein, H. (2009). A user's guide to MLwiN. http://www.bristol.ac.uk/cmm/software/mlwin/download/manual-print.pdf _accessed on $2^{\text {nd }}$ July 2012).

Reeve, C. L., Bonaccio, S. and Charles, J. E. (2008). A policy-capturing study of the contextual antecedents of test anxiety. Personality and Individual Differences 45(3), 243-248. 
Reuer, J. J., Tyler, B. B., Tong, T. W. and Wu, C. W. (2012). Executives' assessments of international joint ventures in China: A multi-theoretical investigation. Management and Organization Review 8(2), 311-340.

Rotundo, M. and Sackett, P. R. (2002). The relative importance of task, citizenship, and counterproductive performance to global ratings of job performance: A policycapturing approach. Journal of Applied Psychology 87(1), 66-80.

Rousseau, D. M. and Anton, R. J. (1988). Fairness and implied contract obligations in job terminations: A policy-capturing study. Human Performance 1(4), 273-289.

Rousseau, D. M. and Anton, R. J. (1991). Fairness and implied contract obligations in job terminations: The role of contributions, promises, and performance. Journal of Organizational Behavior 12(4), 287-299.

Sagiv, L. and Schwartz, S. H. (1995). Value priorities and readiness for out-group social contact. Journal of Personality and Social Psychology 69(3), 437-448.

Schwartz, S. H. (1992). Universals in the content and structure of values: Theoretical advances and empirical tests in 20 countries. Advances in Experimental Social Psychology 25(1), 1-65.

Sen, S., Bhattacharya, C. B. and Korschun, D. (2006). The role of corporate social responsibility in strengthening multiple stakeholder relationships: a field experiment. Journal of the Academy of Marketing Science 34(2), 158-166.

Sheng, S., Zhou, K. Z. and Li, J. J. (2011). The effects of business and political ties on firm performance: evidence from China. Journal of Marketing 75(1), 1-15.

Simon, H. A. (1956). Rational choice and the structure of the environment. Psychological 
Review 63(2), 129-138.

Simon, J. R. (1990). The effects of an irrelevant directional cue on human information processing. In R. W. Proctor and T. G. Reeve (Eds.), Stimulus-Response Compatibility: An Integrated Perspective. Amsterdam: Elsevier.

Sonnentag, S., Binnewies, C. and Mojza, E. J. (2008). “Did you have a nice evening?” A daylevel study on recovery experiences, sleep, and affect. Journal of Applied Psychology 93(3), 674-684.

Sousa, C. M. P. and Bradley, F. (2006). Cultural distance and psychic distance: two peas in a pod? Journal of International Marketing 14(1), 49-70.

Sousa, C. M. P., Ruzo, E. and Losada, F. (2010). The key role of managers' values in exporting: Influence on customer responsiveness and export performance. Journal of International Marketing 18(2), 1-19.

Spence, J. R. and Keeping, L. M. (2010). The impact of non performance information on ratings of job performance: A policy-capturing approach. Journal of Organizational Behavior 31(4), 587-608.

Stanwick, P. A and Stanwick, S. D. (1998). The relationship between corporate social performance, and organizational size, financial performance, and environmental performance: An empirical examination. Journal of Business Ethics 17(2), 195-204.

Steurer, R., Langer, M. E., Konrad, A. and Martinuzzi, A. (2005). Corporations, stakeholders and sustainable development I: a theoretical exploration of business-society relations. Journal of Business Ethics 61(3), 263-281.

Sánchez, C. M. (2000). Motives for corporate philanthropy in EI Salvador: Altruism and 
political legitimacy. Journal of Business Ethics 27(4), 363-375.

Su, J. and He, J. (2010). Does giving lead to getting? Evidence from Chinese private enterprises. Journal of Business Ethics 93(1), 73-90.

Suchman, M. C. (1995). Managing legitimacy: Strategic and institutional approaches. Academy of Management Review 20(3), 571-610.

Swanson, D. L. (1995). Addressing a theoretical problem by reorienting the corporate social performance model. Academy of Management Review 20(1), 43-64.

Trevino, L. K. (1986). Ethical decision making in organizations: A person-situation interactionist model. Academy of Management Review 11(3), 601-617.

Tse, D. K., Pan, Y. and Au, K. Y. (1997). How MNCs choose entry modes and form alliances: the China experience. Journal of International Business Studies 28(4), 779-805.

Turban, D. B. and Greening, D. W. (1997). Corporate social performance and organizational attractiveness to prospective employees. Academy of Management Journal 40(3), 658672.

Tyler, B. B. and Steensma, H. K. (1998). The effects of executives' experiences and perceptions on their assessment of potential technological alliances. Strategic Management Journal 19(10), 939-965.

Usunier, J. C. (1998). International and Cross-Cultural Management Research. London: Sage Publications Ltd.

Venable, B. T., Rose, G. M., Bush, V. D. and Gilbert, F. W. (2005). The role of brand personality in charitable giving: an assessment and validation. Journal of the Academy of Marketing Science 33(3), 295-312. 
Waddock, S. A. and Graves, S. B. (1997). The corporate social performance-financial performance link. Strategic Management Journal 18(4), 303-319.

Webb, D. J., Green, C. L. and Brashear, T. G. (2000). Development and validation of scales to measure attitudes influencing monetary donations to charitable organizations. Journal of the Academy of Marketing Science 28(2), 299-309.

Yin, J. and Zhang Y. (2012). Institutional dynamics and corporate social responsibility (CSR) in an emerging country context: Evidence from China. Journal of Business Ethics 111(2), p.301-316.

Zacharakis, A. L. and Meyer, G. D. (1998). A lack of insight: do venture capitalists really understand their own decision process? Journal of Business Venturing 13(1), 57-76.

Zhang, R., Rezaee, Z. and Zhu, J. (2009). Corporate philanthropic disaster response and ownership type: Evidence from Chinese firms' response to the Sichuan earthquake. Journal of Business Ethics 91(1), 51-63.

Zhang, R., Zhu, J. Yue, H., and Zhu, C. (2010). Corporate philanthropic giving, advertising intensity, and industry competition level. Journal of Business Ethics 94(1), 39-52.

Zhou, J. and Martocchio, J. J. (2001). Chinese and American managers' compensation award decisions: A comparative policy capturing study. Personnel Psychology 54(1), 115145.

Zhou, X. H., Perkins, A. J. and Hui, S. L. (1999). Comparisons of software packages for generalized linear multilevel models. American Statistician 53(3), 282-290. 
Figure 1: Charitable donation in China

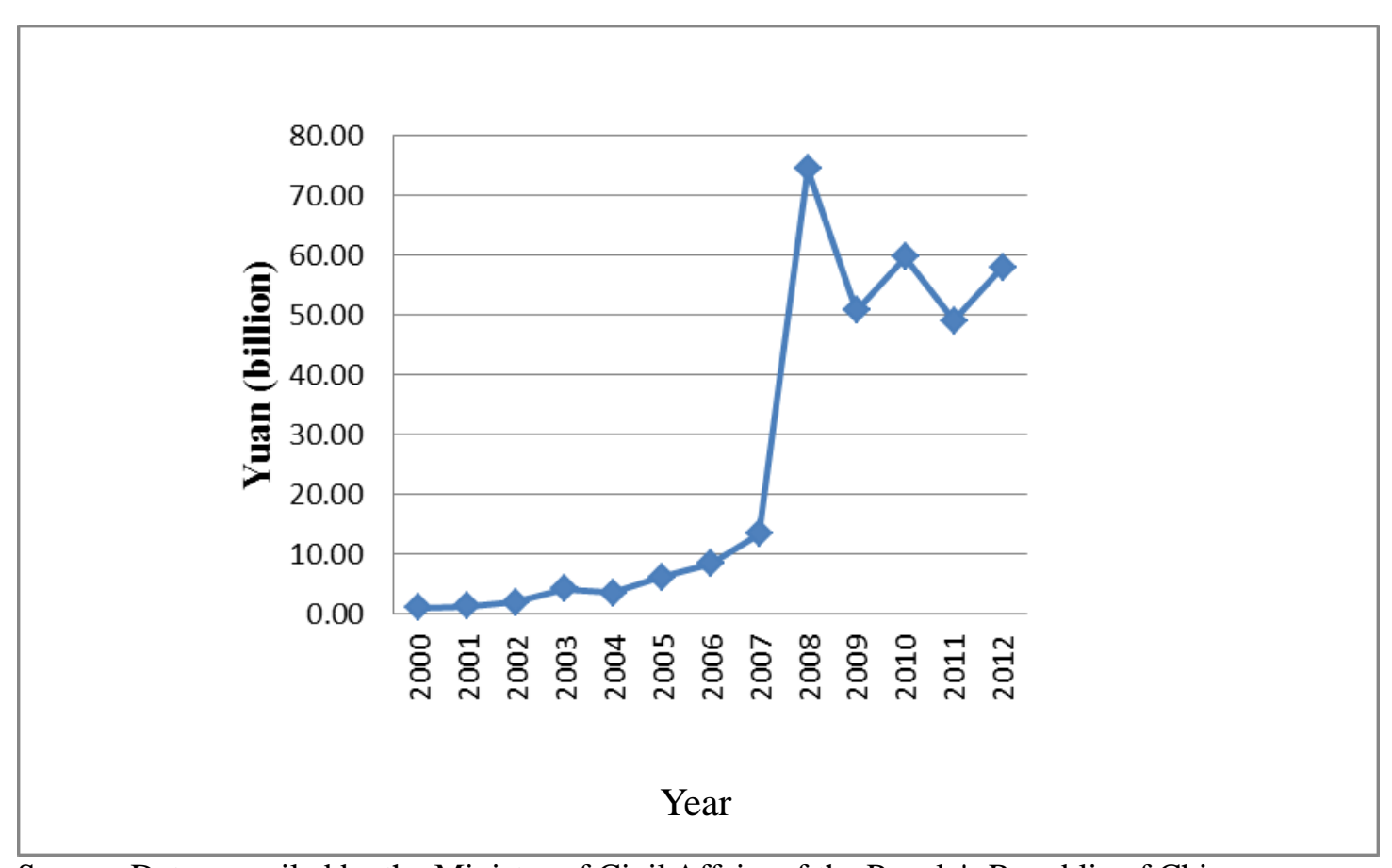

Source: Data compiled by the Ministry of Civil Affairs of the People's Republic of China 
Figure 2: Factors potentially influencing individuals' strategic decisions pertaining to corporate charitable donation

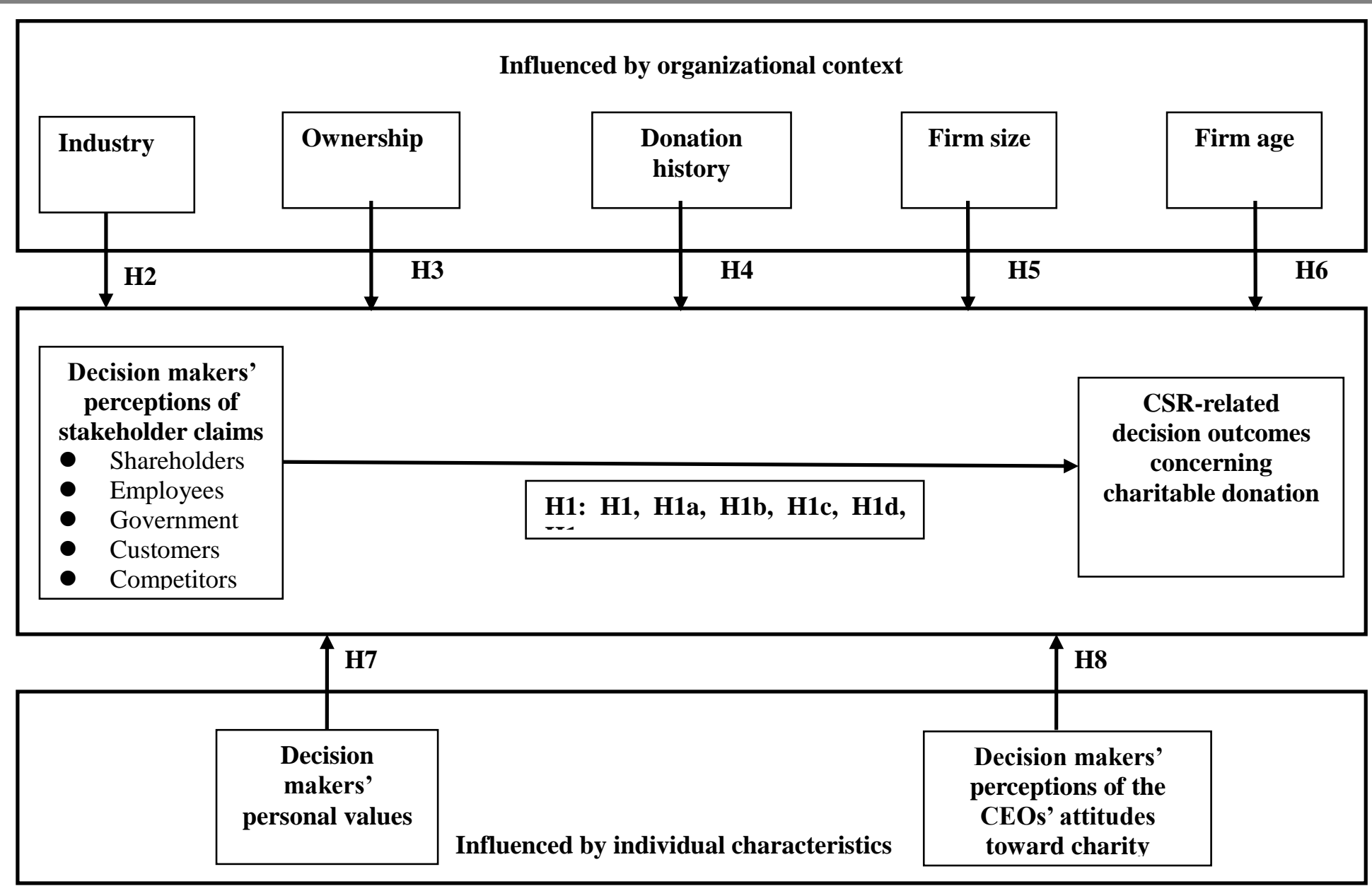


TABLE I

Profile of the research participants

\begin{tabular}{|c|c|c|c|c|}
\hline \multicolumn{2}{|c|}{ Characteristics } & Frequency & Valid Percent & $\begin{array}{c}\text { Cumulative } \\
\text { Percent }\end{array}$ \\
\hline \multirow{5}{*}{ Age } & Less than 25 years & 11 & 3.0 & 3.0 \\
\hline & $25-34$ years & 151 & 40.6 & 43.6 \\
\hline & $35-44$ years & 140 & 37.6 & 81.2 \\
\hline & $45-54$ years & 68 & 18.3 & 99.5 \\
\hline & More than 55 years & 2 & 0.5 & 100.0 \\
\hline \multirow{3}{*}{ Gender } & Total & 372 & 100.0 & \\
\hline & $\begin{array}{l}\text { Male } \\
\text { Female }\end{array}$ & $\begin{array}{l}231 \\
127\end{array}$ & $\begin{array}{l}64.5 \\
35.5\end{array}$ & $\begin{array}{c}64.5 \\
100.0\end{array}$ \\
\hline & Total & 358 & 100.0 & \\
\hline \multirow{6}{*}{ Education } & Junior middle school & 1 & 0.3 & 0.3 \\
\hline & Bachelor degree & 263 & 71.3 & 72.4 \\
\hline & Masters degree & 93 & 25.2 & 97.6 \\
\hline & Doctoral degree & 3 & 0.8 & 98.4 \\
\hline & Others & 6 & 1.6 & 100.0 \\
\hline & Total & 369 & 100.0 & \\
\hline \multirow{6}{*}{$\begin{array}{l}\text { Current } \\
\text { Position }\end{array}$} & CEO & 35 & 9.9 & 9.9 \\
\hline & Other executive & 78 & 22.0 & 31.9 \\
\hline & Middle manager & 123 & 34.7 & 66.7 \\
\hline & Other manager & 42 & 11.9 & 78.5 \\
\hline & Others & 76 & 21.5 & 100.0 \\
\hline & Total & 354 & 100.0 & \\
\hline \multirow{4}{*}{$\begin{array}{c}\text { Work } \\
\text { experience }\end{array}$} & $\begin{array}{l}3-10 \text { years } \\
11-20 \text { vears }\end{array}$ & 144 & 40.6 & 40.6 \\
\hline & $\begin{array}{l}11-20 \text { years } \\
21-30 \text { years }\end{array}$ & $\begin{array}{l}153 \\
66\end{array}$ & 18.6 & 96.6 \\
\hline & More than 30 years & 12 & 3.4 & 100.0 \\
\hline & Total & 355 & 100.0 & \\
\hline \multirow{4}{*}{$\begin{array}{c}\text { Current } \\
\text { education } \\
\text { and training } \\
\text { programs }\end{array}$} & EMBA & 137 & 36.4 & 36.4 \\
\hline & MBA & 74 & 19.7 & 56.1 \\
\hline & Training & 165 & 43.9 & 100.0 \\
\hline & Total & 376 & 100.0 & \\
\hline
\end{tabular}


TABLE II

Correlations between stakeholder decision cues

\section{Shareholders Employees Government Customers Competitors}

Shareholders

Employees $\quad .02$

Government $\quad .13$

$\begin{array}{llll}\text { Customers } & -.02 & .02 & .13\end{array}$

$\begin{array}{lllll}\text { Competitors } & -.16 & .16 & .00 & -.16\end{array}$

Note: no correlation was significant $(\mathrm{p}<.05)$. 
TABLE III: Means, Standard Deviations (S.D.), and Correlations of the study variables ${ }^{\text {a }}$

\begin{tabular}{|c|c|c|c|c|c|c|c|c|c|c|c|c|c|c|}
\hline & $\mathrm{M}$ & S.D. & 1 & 2 & 3 & 4 & 5 & 6 & 7 & 8 & 9 & 10 & 11 & 12 \\
\hline 1. Scenarios scores ${ }^{b}$ & 86.72 & 12.17 & & & & & & & & & & & & \\
\hline 2. Resultant self-enhancement ${ }^{c}$ & -.74 & 1.10 & $-.07^{*}$ & - & & & & & & & & & & \\
\hline 3. CEO attitudes ${ }^{\mathrm{d}}$ & 1.51 & .50 & $.31^{* *}$ & $-.21^{* *}$ & - & & & & & & & & & \\
\hline 4. Firm ownership ${ }^{e}$ & .57 & .50 & .08 & $-.15^{* *}$ & .04 & - & & & & & & & & \\
\hline 5. Firm size ${ }^{f}$ & .32 & .47 & $.11^{*}$ & .04 & -.07 & $.15^{*}$ & - & & & & & & & \\
\hline 6. Firm age ${ }^{g}$ & .36 & .48 & $.16^{* *}$ & -.09 & .01 & $.48^{* *}$ & $.16^{* *}$ & - & & & & & & \\
\hline 7. Donation history ${ }^{h}$ & .32 & .47 & $.30^{* *}$ & -.05 & $.20^{* *}$ & $.19^{* *}$ & $.41^{* *}$ & $.15^{* *}$ & - & & & & & \\
\hline 8. Industry ${ }^{\mathrm{i}}$ & .55 & .50 & $.22^{* *}$ & $-.23^{* *}$ & .10 & $.46^{* *}$ & .02 & $.30^{* *}$ & $.36^{* *}$ & - & & & & \\
\hline 9. Age $^{\mathrm{j}}$ & 2.73 & .81 & .03 & $-.22^{* *}$ & .07 & $.28^{* *}$ & .08 & $.15^{* *}$ & .09 & $.23^{* *}$ & - & & & \\
\hline 10. Gender ${ }^{\mathrm{k}}$ & 1.35 & .48 & .07 & -.07 & .03 & .05 & -.08 & -.03 & -.01 & $.16^{*}$ & $-.20^{* *}$ & - & & \\
\hline 11. Education degree ${ }^{1}$ & 3.30 & .60 & -.05 & .09 & .02 & .06 & .00 & .07 & .05 & .04 & $.11^{*}$ & .03 & - & \\
\hline 12. Position ${ }^{\mathrm{m}}$ & 1.41 & .49 & -.05 & -.01 & -.03 & $-.18^{* *}$ & -.05 & -.04 & $-.19^{* *}$ & $-.32^{* *}$ & $.30^{* * *}$ & .00 & .06 & \\
\hline 13. Work experience (years) & 14.54 & 8.76 & -.02 & $-.24^{* *}$ & .10 & $.25^{* *}$ & .05 & $.12^{*}$ & .02 & $.19^{*}$ & $.90^{* *}$ & $-.23^{* *}$ & .08 & $.32^{* *}$ \\
\hline
\end{tabular}

Notes: ${ }^{\mathrm{a}} \mathrm{N}=376 ;{ }^{\mathrm{b}}$ Scenario scores $=$ the total scores of the 16 scenarios. ${ }^{\mathrm{c}}$ Resultant self-enhancement $(0=$ lower level and $1=$ higher level $) .{ }^{\mathrm{d}} \mathrm{CEO}$ attitudes $=$ CEOs' attitudes toward charity donation and charitable organizations $(0=$ lower level, below 45 and $1=$ higher level, above 45$)$. ${ }^{\mathrm{e}}$ Firm ownership $(0=$ non-SOEs and $1=$ SOEs $) .{ }^{\mathrm{f}}$ Firm size $(0=$ small and medium size, employees $\leq 1500$ and $1=$ large size, employees $>1500)$. ${ }^{\mathrm{g}}$ Firm age $(0=$ younger firm, $\leq 21$ years and $1=$ older firm, $>21$ years $)$. ${ }^{\mathrm{h}}$ Previous donation $(0=$ lower level $\leq 1$ million $\mathrm{RMB}$ and $1=$ higher level $>1$ million RMB ). ${ }^{\mathrm{i}}$ Industry ( $0=$ manufacturing and mining industry and $1=$ financial service industry). ${ }^{\mathrm{j}}$ Age $(1=$ below $25,2=25-34,3=35-44,4=45$ $54,5=55+) .{ }^{\mathrm{k}}$ Gender $\left(1=\right.$ male, $2=$ female). ${ }^{1}$ Education degree $(1=$ junior middle school, $2=$ senior middle school, $3=$ bachelor degree, $4=$ master degree, $5=$ doctoral degree); ${ }^{\mathrm{m}}$ Position= managers' current position $(1=$ middle manager, $2=\mathrm{CEO}$ or other executive $)$. p $<.05 ;{ }^{* *} \mathrm{p}<.01$ 
TABLE IV

Multiple regression models of stakeholder cues on CSR-related SDM concerning charitable donations

\begin{tabular}{lcccccc}
\hline \hline Variable & Parameter & $\mathrm{SE}^{\mathrm{a}}$ & Ratio & Variance $^{\mathrm{b}}$ & $\mathrm{SE}$ & Ratio \\
\hline Intercept, $\beta_{0}$ & $5.01^{* * * *}$ & .06 & 84.86 & $.68^{* * * *}$ & .08 & 8.40 \\
Shareholder, $\beta_{1}$ & $.08^{*}$ & .04 & 2.02 & $.31^{* * *}$ & .05 & 6.49 \\
Employee, $\beta_{2}$ & $-.09^{* *}$ & .03 & -2.81 & $.07^{*}$ & .03 & 2.24 \\
Government, $\beta_{3}$ & $.22^{* * *}$ & .04 & 6.34 & $.15^{* * *}$ & .04 & 4.29 \\
Customer, $\beta_{4}$ & $.37^{* * *}$ & .03 & 11.24 & $.07^{*}$ & .03 & 2.19 \\
Competitor, $\beta_{5}$ & $.11^{* * *}$ & .03 & 3.80 & .00 & .00 & \\
Effect size $(\%)^{\mathrm{c}}$ & & & & & & \\
\hline
\end{tabular}

Note. $\mathrm{N}=6016$. The stakeholder (i.e., shareholder, employee, government, customer, and competitor) represents the concerning stakeholder claims.

${ }^{a}$ Average estimated SE of the Level 1 regression coefficients. ${ }^{b}$ Variance in Level 1 parameter estimates and t-test of significance of variance.

${ }^{\mathrm{c}}$ Percentage of explainable Level 1 variance in the dependent variable accounted for by stakeholder claims. 


\section{TABLE V}

\section{Influence analysis of organizational and individual characteristics}

(Dependent variable: scenario scores)

\begin{tabular}{|c|c|c|c|c|c|c|}
\hline \multirow{2}{*}{$\begin{array}{l}\text { Independent } \\
\text { variables }\end{array}$} & Paramete & SE & Ratio & Parameters & SE & Ratio \\
\hline & \multicolumn{3}{|c|}{ Industry (financial service) } & \multicolumn{3}{|c|}{$\begin{array}{l}\text { Previous Company Donation } \\
\text { (above } 1.0 \text { million RMB) }\end{array}$} \\
\hline Intercept, $\beta_{0 \mathrm{j}}$ & $4.81^{* * * *}$ & .12 & 40.73 & $4.79^{* * * *}$ & .07 & 67.39 \\
\hline Shareholder, $\beta_{1 \mathrm{j}}$ & $.14^{*}$ & .06 & 2.26 & .07 & .05 & 1.60 \\
\hline Employee, $\beta_{2 j}$ & $-.10^{*}$ & .05 & -1.98 & $-.11^{* *}$ & .04 & -2.92 \\
\hline Government, $\beta_{3 j}$ & $.17^{* *}$ & .06 & 2.95 & $.23^{* * * *}$ & .04 & 5.95 \\
\hline Customer, $\beta_{4 j}$ & $.47^{* * *}$ & .06 & 7.90 & $.37^{* * * *}$ & .04 & 10.69 \\
\hline Competitor, $\beta_{5 \mathrm{j}}$ & .08 & .05 & 1.73 & $.13^{* * * *}$ & .03 & 3.91 \\
\hline Factor $(O)^{a}, \beta_{6 j}$ & $.34^{* *}$ & .12 & 2.90 & $.49^{* * * *}$ & .08 & 6.35 \\
\hline \multirow[t]{2}{*}{ Effect size $^{\mathrm{b}}(\%)$} & .00 & & & 4.11 & & \\
\hline & \multicolumn{3}{|c|}{ Firm Size (above 1500) } & \multicolumn{3}{|c|}{ Firm Age (above 21 years) } \\
\hline Intercept, $\beta_{0 j}$ & $4.93^{* * * *}$ & .07 & 73.60 & $4.90^{* * *}$ & .07 & 69.01 \\
\hline Shareholder, $\beta_{1 \mathrm{j}}$ & $.09^{*}$ & .04 & 2.02 & $.09^{*}$ & .04 & 2.12 \\
\hline Employee, $\beta_{2 j}$ & $-.09^{* *}$ & .03 & -2.62 & $-.08^{*}$ & .03 & -2.38 \\
\hline Government, $\beta_{3 j}$ & $.22^{* * *}$ & .04 & 6.03 & $.22^{* * *}$ & .04 & 5.87 \\
\hline Customer, $\beta_{4 j}$ & $.36^{* * * *}$ & .03 & 10.68 & $.37^{* * * *}$ & .04 & 10.22 \\
\hline Competitor, $\beta_{5 \mathrm{j}}$ & $.12^{* * *}$ & .03 & 3.94 & $.12^{* * * *}$ & .03 & 3.59 \\
\hline Factor $(O), \beta_{6 j}$ & $.18^{*}$ & .08 & 2.16 & $.26^{* * * *}$ & .08 & 3.19 \\
\hline Effect size (\%) & .00 & & & .00 & & \\
\hline
\end{tabular}




\begin{tabular}{|c|c|c|c|c|c|c|}
\hline \multirow[b]{2}{*}{ Intercept, $\beta_{0 j}$} & \multicolumn{3}{|c|}{$\begin{array}{l}\text { Personal Values (resultant } \\
\text { self-enhancement) }\end{array}$} & \multicolumn{3}{|c|}{ Attitudes (higher level) } \\
\hline & $4.97^{* * * *}$ & .07 & 76.40 & $4.28^{* * * *}$ & .13 & 32.68 \\
\hline Shareholder, $\beta_{1 \mathrm{j}}$ & $.08^{*}$ & .04 & 2.02 & $.08^{*}$ & .04 & 1.98 \\
\hline Employee, $\beta_{2 j}$ & $-.09^{* *}$ & .03 & -2.81 & $-.09^{* *}$ & .03 & -2.94 \\
\hline Government, $\beta_{3 j}$ & $.22^{* * * *}$ & .04 & 6.34 & $.22^{* * * *}$ & .04 & 6.31 \\
\hline Customer, $\beta_{4 j}$ & $.37^{* * * *}$ & .03 & 11.24 & $.37^{* * * *}$ & .03 & 11.27 \\
\hline Competitor, $\beta_{5 \mathrm{j}}$ & $.11^{* * * *}$ & .03 & 3.80 & $.11^{* * * *}$ & .03 & 3.80 \\
\hline Factor $(\mathrm{I})^{\mathrm{c}}, \beta_{6 \mathrm{j}}$ & $-.07^{*}$ & .04 & -2.03 & $.48^{* * * *}$ & .07 & 6.42 \\
\hline Effect size $(\%)$ & .00 & & & .00 & & \\
\hline
\end{tabular}

Note. ${ }^{a}$ Factor $(\mathrm{O})$ represents the organizational factors (i.e. firm industry, previous company donation, firm size, and firm age). ${ }^{\mathrm{b}}$ Percentage of explainable variance in the dependent variable accounted for the concerning individual or organizational characteristics. ${ }^{\mathrm{c}}$ Factor (I) represents the individual factors (i.e., personal values and CEOs' attitudes toward charity). ${ }^{*} \mathrm{p}<.05,{ }^{* *} \mathrm{p}<.01$, and ${ }^{* * *} \mathrm{p}<.001$ 